\title{
Formação profissional em serviço social e gênero: algumas considerações*
}

Professional formation in Social Work and Gender: some considerations

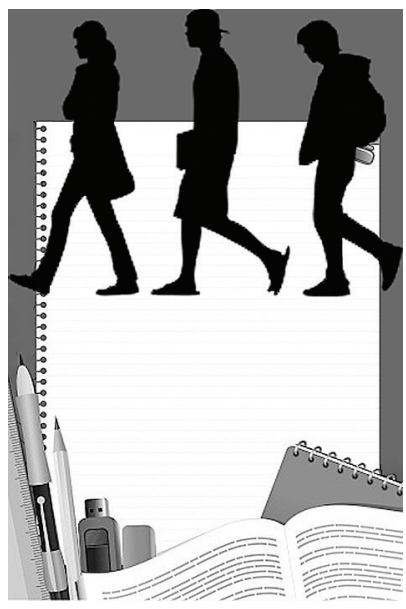

Rita de Lourdes de Lima**

Resumo: Este artigo apresenta os resultados da pesquisa realizada com 32 universidades do Brasil. Foram aplicados 54 questionários com docentes e discentes dos cursos de Serviço Social presenciais, com o objetivo de conhecer a realidade do ensino das disciplinas, grupos de estudo e pesquisadores ligados às questões de gênero. Os dados mostram que em todos os cursos pesquisados há disciplinas, grupos e pesquisadores ligados à temática de gênero. As disciplinas são eletivas e ofertadas no final do curso. Há em torno de três a quatro pesquisadores e um grupo de pesquisa por universidade. É necessário redefinir a inclusão do tema na graduação.

Palavras-chave: Serviço Social. Gênero. Formação profissional. Graduação.

\begin{abstract}
This article presents the results of the research done in 32 Brazilian universities. Fiftyfour questionnaires were answered by professors and students of classroom Social Work courses in order to know the reality of the teaching of the disciplines, study groups and researchers linked to gender issues. The results show that in every course researched there are disciplines, groups and researchers linked to the gender issue. The disciplines are elective and taken at the end of the course. There are about 3 or 4 researchers and 1 group of study per university. It is necessary to redefine the insert of the theme in the graduation course.
\end{abstract}

Keywords: Social Work. Gender. Professional formation. Graduation.

* Pesquisa desenvolvida durante o estágio pós-doutoral realizado na Universidade Federal do Rio de Janeiro. Parte desta análise consta no relatório do estágio pós-doutoral apresentado ao PPGSS/UFRJ em 2012.

** Mestre e doutora em Serviço Social pela Universidade Federal de Pernambuco (UFPE), professora do Departamento e do Programa de Pós-Graduação em Serviço Social da Universidade Federal (UFRN), Natal, Brasil.E-mail: rita.pires2@gmail.com. 


\section{Introdução}

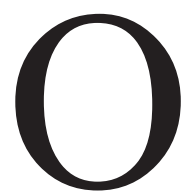

surgimento do Serviço Social se situa na transição do capitalismo concorrencial ao monopolista a partir das exigências deste que, no seu processo de expansão crescente, passou a exigir profissionais capacitados para as funções de articulação da população, operando com a coerção e a construção de consensos com vistas a contribuir para a atenuação dos conflitos sociais. A profissão se realiza, portanto, na disjunção entre os que demandam seus serviços - o Estado ou patronato - e aqueles que o recebem - os(as) trabalhadores(as) (Iamamoto, 1983).

Neste sentido, o Serviço Social é, segundo Iamamoto (Idem), uma tecnologia social e o(a) assistente social um(a) técnico(a) cuja atuação é geralmente mediatizada pela prestação de serviços sociais em instituições que implementam políticas sociais.

Assim caracterizado, o Serviço Social, como todas as demais profissões, nasceu em conjunturas históricas que exigiam novas formas de atuação frente às necessidades sociais. No caso do Serviço Social, foi o surgimento e a agudização da "questão social", que demandou a atuação de profissionais capacitados para lidar com a administração desta questão.

Além da sua relação intrínseca com a questão social, são três as características marcantes presentes no nascimento da profissão: a) sua ligação às doutrinas religiosas (sejam elas católicas ou protestantes - essa associação com uma ou outra religião dependerá da história do país de origem); b) sua ligação à classe burguesa; c) e, por fim, sua constituição como uma profissão de e para mulheres.

Deste modo, a história do Serviço Social no Brasil e no mundo tem sido construída por mulheres. Vários estudos mostram a predominância feminina na profissão e analisam às consequências de tal fato para o Serviço Social. ${ }^{2}$

Acerca do Serviço Social no Brasil, hoje, Iamamoto (1998, p. 104) afirma: "Com tal perfil (feminino), o assistente social absorve tanto a imagem social da mulher, quanto às discriminações a ela impostas no mercado de trabalho [...]”.

1. Para uma discussão acerca da relação entre o Serviço Social e a "questão social" ver, entre outros, Iamamoto, 1998 e 2002.

2. A esse respeito, ver Heckert, 1991; Iamamoto, 1998; Verdes-Leroux, 1986; Veloso, 2001 e Lima, 2005. 
Observa-se, portanto, que muitos dos traços do início da profissão permanecem, mas o que mais parece resistir ao tempo é a predominância feminina. Pesquisa coordenada pelo Conselho Federal de Serviço Social (CFESS, 2005) no Brasil, mostra que $97 \%$ dos assistentes sociais do Brasil são mulheres. ${ }^{3}$

A explicação para essa predominância deve-se ao fato de a subjetividade feminina, na forma como foi e é construída socialmente, apresentar a mulher como "um ser para os outros", que tende a desprezar o próprio desejo frente aos do marido e filhos, que aceita um lugar secundário na distribuição de recursos e benefícios grupais, sacraliza as funções de mãe e esposa, associando a estas as qualidades de fragilidade, intuição, abnegação, docilidade, sensibilidade, entre outras (Rocha-Coutinho, 1994). Essa constante associação feminino-docilidade-maternidade-abnegação liga-se às representações sobre o feminino que se mantêm ao longo das gerações, apesar dos questionamentos.

Neste sentido, as chamadas "profissões femininas" - e entre elas encontra-se o Serviço Social — são mais procuradas por mulheres justamente porque tais profissões exigem dos(as) profissionais docilidade, sensibilidade, serviço ao outro, abnegação etc. As mulheres, que tiveram sua subjetividade construída a partir desses atributos, encontram sua "vocação" nessas profissões, pois estas remetem a valores que lhes foram ensinados ao longo da vida (Bourdieu, 1999).

Observa-se, portanto, que o imbricamento entre o "ser mulher" e o Serviço Social se faz presente na experiência do Serviço Social não só no Brasil, mas em várias partes do mundo.

Ora, apesar desse imbricamento, as discussões de gênero no Serviço Social brasileiro começaram a tomar forma somente em finais dos anos 1990. A discussão de gênero adquire certa importância nas diretrizes curriculares para os cursos de graduação de Serviço Social, aprovadas pela Associação Brasileira de Ensino e Pesquisa em Serviço Social (ABEPSS) em 1996, sendo considerada uma discussão que deve perpassar a formação profissional. Contudo, apesar dessa constatação, não é assim que a formação profissional vem se dando efetivamente.

Conversas informais com discentes do curso de graduação em Serviço Social e do mestrado em Serviço Social da UFRN mostram que a discussão de gênero encontra-se, na maioria das vezes, ausente na formação profissional, apesar de ser considerado por todos(as) um assunto que deve ser discutido e que deve fazer par-

3. A pesquisa denominou-se "Perfil profissional do assistente social no Brasil" e trabalhou com todos os estados brasileiros, exceto o Acre. 
te da formação discente, por tratar-se de uma profissão com predominância feminina e, portanto, com um forte recorte de gênero.

Essas conversas informais levaram-nos a desejar investigar mais profundamente a formação do assistente social no Brasil, por tratar-se do país no qual exerço a docência. Assim, pareceu-nos oportuno investigar até que ponto as discussões de gênero se fazem presentes na formação dos(as) futuros(as) assistentes sociais no Brasil, buscando avaliar as implicações de uma possível ausência dessas discussões.

Traçamos como estratégia conseguir os dados durante a realização da Oficina Nacional da Abepss, nos dias 21 e 22 de novembro de 2011, na UFRJ, para a qual os cursos presenciais de Serviço Social filiados à Abepss enviariam representantes tanto de universidades públicas como privadas. No evento entregamos cerca de 230 questionários a docentes e discentes, independente de qual universidade faziam parte. Recebemos devidamente respondidos 54 questionários, os quais analisamos a fim de obter uma aproximação inicial com a realidade das discussões de gênero nos cursos de Serviço Social no Brasil.

Os dados analisados mostram que na maioria das universidades do Brasil as disciplinas que tratam da temática de gênero se dão predominantemente de forma eletiva, ou seja, os(as) discentes podem terminar o curso de Serviço Social sem cursá-las. Quando são ofertadas, o são a partir do $5^{\circ}$ período do curso, mas há muitas universidades nas quais a oferta só se dá no $7^{\circ}$ ou $8^{\circ}$ período, ou seja os(as) discentes já têm passado pela experiência do estágio curricular obrigatório. Deste modo, as questões de gênero, raça/etnia podem passar despercebidas aos discentes, pois a formação profissional no Serviço Social enfatiza a questão das classes sociais, mas por vezes esquece-se que ligada à classe social encontram-se as mediações de gênero, raça/etnia e orientação sexual, mediações importantíssimas a serem problematizadas no processo de formação profissional.

Para apresentar os resultados dessa pesquisa e análise dividimos este trabalho em três itens, além desta introdução e considerações finais. Na primeira, realizamos uma primeira aproximação ao objeto, discutindo o Serviço Social como profissão inserida na divisão sexual do trabalho, mostrando como tal determinante ainda secciona as profissões e atividades em masculinas e femininas. Em seguida tecemos algumas considerações sobre o ensino do Serviço Social no Brasil, analisando a conjuntura adversa em que tem se dado o ensino presencial no Brasil, na qual prolifera o aligeiramento dos processos formativos em detrimento da qualidade. Por fim, apresentamos o caminho teórico-metodológico percorrido por nós na coleta de 
dados e analisamos os questionários aplicados com docentes e discentes de 32 universidades, propondo sugestões para o ensino de Serviço Social no Brasil, especificamente no que se refere às discussões de gênero.

\section{A divisão sexual do trabalho, as mulheres e o Serviç̧o Social no Brasil}

O Brasil teve seu processo de colonização com base na religião católica e, consequentemente, teve seus valores alicerçados no imaginário judaico-ocidental cristão. Neste sentido, tal imaginário, aliado a determinadas peculiaridades da formação socioeconômica brasileira, fizeram surgir e tornar-se hegemônico o modelo familiar patriarcal brasileiro, a partir do ciclo da cana de açúcar no Nordeste.

O modelo de família patriarcal dominante no Nordeste brasileiro ${ }^{4}$ enfatizava a autoridade máxima do pai de família sobre todos os outros membros familiares, poder incontestável. ${ }^{5} \mathrm{Tal}$ poder se estendia a parentes e agregados, pois as famílias eram, na verdade, extensos clãs que serviam para legitimar e garantir o poder de seu chefe. Os casamentos, em geral, visavam a unir famílias importantes e contavam com controle de sexualidade e regulação da procriação com vistas à questão da herança e sucessão ${ }^{6}$ (Osterne, 2001).

A estrutura econômica de base agrária, latifundiária e escravocrata do Brasil colonial - associada a outras condições, tais como descentralização administrativa local, excessiva concentração fundiária e acentuada dispersão populacional — determinou a instalação de uma sociedade paternalista, na qual as relações de natureza pessoal se tornaram deveras importantes. (Osterne, 2001, p. 60)

Assim, características específicas da nossa sociedade farão do homem não só o chefe da família, mas também o patriarca, o coronel, o dono do poder econômico e político. Esse era o tipo de família hegemônico no Brasil do século XVI ao XIX, e toda a nossa formação social deriva daí.

4. A família nuclear burguesa como a conhecemos hoje só surge no século XVII.

5. O modelo familiar brasileiro desse período compreendia pai, mãe, filhos e agregados em geral (afilhados, primos, sobrinhos etc., qualquer um que morasse na casa-grande sob a autoridade do homem).

6. Tal organização, entretanto, contrastava com a organização familiar plebeia, na qual predominava mancebia, ligação transitória e poliandria difusa (Osterne, 2001). 
Com a chegada da família real portuguesa ao Brasil, o modelo de família patriarcal brasileiro sofre modificações trazidas pela nova realidade de maior desenvolvimento urbano e costumes europeus. Soma-se posteriormente a isso a realidade urbana, a industrialização, o fim da escravidão. Contudo, o atual modelo familiar, baseado agora somente no pai, mãe e filhos, não interfere na sua matriz patriarcal, ou seja, o novo modelo incorporou o patriarcalismo ao invés de derrubá-lo.

Com o advento da modernidade ${ }^{7}$ surgiram movimentos que possibilitaram o questionamento e a queda de preconceitos históricos contra as mulheres. Contudo, a modernidade também se estruturou alicerçada no pensamento cristão, o que estabeleceu a permanência de inúmeras contradições em seu interior. Deste modo, o movimento feminista surgiu na modernidade e ganhou proporções mundiais, lutando por sufrágio universal e posteriormente — no século XX — ampliando suas lutas.

O feminismo, ${ }^{8}$ como os demais movimentos sociais, atravessou momentos de crescimento e retrocesso. Pode-se assinalar a década de 1960 como o período do ressurgimento dos movimentos sociais em geral ${ }^{9}$ e o movimento feminista, à semelhança dos demais, teve um dos seus ápices nas décadas de 1960 e 1970.

É desse período uma grande variedade de fenômenos que expressaram a rejeição das mulheres feministas ao modelo tradicional de mulher. Cresciam em todo o mundo as manifestações maciças exigindo mudanças na legislação, que se concretizaram em numerosos países entre 1970 e 1980 (Ergas, 1991).

Assim, com a ocupação crescente do espaço público pelas mulheres, as reivindicações vão se ampliando e estabelecendo o direito ao aborto, ao divórcio, ao livre exercício da sexualidade etc. (Toscano e Goldenberg, 1992). ${ }^{10}$ Com o cresci-

7. Por modernidade entendemos o período histórico que começou, na Europa Ocidental, no século XVII. Consiste em uma série de transformações socioestruturais e intelectuais profundas que atingiu a maturidade primeiramente como projeto cultural, com o avanço do Iluminismo, e depois como forma de vida socialmente consumada com o desenvolvimento da sociedade industrial capitalista. A modernidade traz a ideia de aperfeiçoamento e progresso com base na racionalidade (explicação do mundo) e na dominação da natureza, envolvendo o conceito de ruptura com a tradição (Tarnas, 2000).

8. "O feminismo [...] indica historicamente conjuntos variados de teorias e práticas centradas em volta da constituição e da legitimação dos interesses das mulheres. Nesta perspectiva, o feminismo é mais uma questão histórica do que uma questão de definição" (Ergas, 1991, p. 588).

9. Esse é o período dos questionamentos a todas as formas de controle - movimento hippie, minissaias, revoluções sociais e políticas, invenção da pílula anticoncepcional etc.

10. As conquistas dos movimentos feministas vão ter especificidades em cada país. Na França, por exemplo, a legalização do divórcio se deu em 1792, mas o direito de voto somente em 1944. No Brasil, o direito de voto é reconhecido em 1932 e o divórcio bem tardiamente, em 1977. 
mento do movimento feminista, ele passa a chamar a atenção do mundo e, então, se torna objeto de estudo acadêmico já a partir da década de 1960 (Fonseca, 1995).

Desse modo, as discussões e análises na academia levaram ao surgimento e à expansão do conceito de gênero. A primeira utilização do termo data de 1955 e foi proposto por John Money para descrever o conjunto de condutas atribuídas aos homens e às mulheres. Contudo, a diferença conceitual entre gênero e sexo foi nitidamente definida por Robert Stoller em 1968. Esse autor definiu sexo como o aspecto anatômico e fisiológico da espécie humana e gênero como relacionado ao significado que cada sociedade atribui ao sexo (Gomáriz, 1992).

Tal conceituação foi retomada pelo movimento feminista e se constitui numa "ferramenta útil" para discutir as diferenças socialmente construídas entre os sexos. ${ }^{11}$

Os sistemas de gênero/sexo são os conjuntos de práticas, símbolos, representações, normas e valores sociais que as sociedades elaboram a partir da diferença sexual anatômico-fisiológica e que dão sentido à satisfação dos impulsos sexuais, à reprodução da espécie humana e, em geral, ao relacionamento entre as pessoas. (Barbieri, 1993, p. 4)

Segundo Scott (1990), as feministas começaram a utilizar gênero como uma forma de se referir à organização social da relação entre os sexos, e o conceito indicava, antes de tudo, rejeição ao determinismo biológico.

A expansão do movimento feminista mostrou que as mulheres, ao mesmo tempo em que têm uma identidade social que as unifica enquanto mulheres, têm também sua identidade construída em torno de outros elementos que as diferenciam: a orientação sexual, a raça/etnia, a classe social, a cultura de seus respectivos países, a ideologia política e, por fim, a corrente do feminismo que defendem. Assim, junto com o movimento feminista cresceu também a discussão na academia e foram surgindo diversas correntes em seu interior.

Nessas diferentes perspectivas, sempre ocuparam lugar de destaque as discussões sobre a relação produção-reprodução. Há os que defendem que a esfera doméstica está sobredeterminada pela produção de bens e serviços (algumas abordagens marxistas); outros apontam que a vida familiar, afetiva, maternagem e sexualidade, condicionam a forma de uso e controle da força de trabalho feminina, e há aqueles

11. Outras feministas optaram pelo conceito "relações sociais de sexo". Tal escolha se deu principalmente entre feministas francesas ligadas ao marxismo. Aqui optamos por "gênero", pois é o termo mais utilizado no Brasil. 
que tentam romper com esse raciocínio de causalidade unilateral, estabelecendo a múltipla e mútua influência entre produção e reprodução.

De todas essas, tendemos a concordar com a postura marxista, apesar das críticas feitas a seu suposto reducionismo econômico. A nosso ver, a grande contribuição das abordagens marxistas é o contínuo chamamento de nossa atenção para a relação dos fenômenos com a organização social, afirmando que homens e mulheres são, antes de tudo, seres sociais e, como tais, condicionados histórica e socialmente. Portanto, nossos valores, preconceitos, construção identitária, nossa forma de agir e sentir são produtos sociais. Neste sentido, a produção e a reprodução formam um só e único processo, no qual há mútua e múltipla influência. ${ }^{12}$

Neste sentido, a realidade é um processo de vir a ser permanente e suas transformações se dão histórica e socialmente a partir da práxis humana, e por meio dela os homens e as mulheres transformam a realidade, ao mesmo tempo em que são transformados por ela (Marx, 1991, 1987; Vásquez, 2007). Deste modo, todos os domínios da vida humana formam uma totalidade dialética que interagem entre si, modificando-se e modificando os homens/mulheres neste processo.

Nessa perspectiva, "a representação é a subjetivação da objetividade que, na condição de mola propulsora da ação, volta para o mundo da objetividade" (Saffioti, 2000, p. 74). A nosso ver, portanto, a relação entre feminismo e marxismo é salutar e enfatiza uma perspectiva teórica que se recusa a separar a materialidade da vida do seu significado.

Apesar da complexidade das relações sociais e dos múltiplos elementos nelas envolvidos, tendeu-se a uma divisão dicotômica do mundo (pobre/rico, alto/baixo, homem/mulher, branco/negro, produção/reprodução, público/privado, entre outras), e isso refletiu-se no mundo do trabalho, no qual coube ao homem o espaço da produção e do domínio público, e à mulher, o espaço da reprodução e a esfera privada.

Deste modo, as "escolhas" profissionais feitas pelo indivíduo se encontram ligadas às construções sociais feitas acerca dos gêneros.

Ora, as questões ligadas às escolhas profissionais e à divisão do trabalho social entre homens e mulheres passaram a preocupar uma parte das estudiosas feministas, e isso levou-as a estudar particularmente o mundo do trabalho, no que se referia às

12. É mister, entretanto, assinalar que prevaleceu nas análises marxistas a ausência de um enfoque mais aprofundado sobre o impacto da subjetividade e das representações na construção do social, estabelecendo por vezes um vínculo excessivamente mecânico entre a base econômica e modificações nos valores e padrões culturais (Araújo, 2000). Contudo, constitui-se também um equívoco a ênfase na dimensão subjetiva das relações de poder entre homens e mulheres, desvinculada da sua base material. 
desigualdades entre homens e mulheres (diferenças salariais, profissões masculinas e femininas, diferentes condições de trabalho etc.). Tais estudos se dedicam à divisão sexual do trabalho.

O termo divisão sexual do trabalho é utilizado na linguagem sociológica com acepções muito diferentes, contudo ele remete em geral a uma abordagem descritiva explicativa, na qual se mostra que há uma diferenciação entre os sexos nas atividades sociais, tentando encontrar explicações para as permanências ou modificações que se dão na divisão do trabalho social entre os sexos. ${ }^{13}$

Acerca da divisão sexual do trabalho, Kergoat (1984, p. 134 e 280-281) assinala:

A divisão sexual do trabalho é sempre indissociável das relações sociais entre homens e mulheres, que são relações desiguais, hierarquizadas, assimétricas e antagônicas. [...] a divisão sexual do trabalho é sempre estruturada por um princípio hierárquico: o trabalho masculino tem sempre um valor superior ao trabalho feminino. (Tradução nossa)

Os estudos sobre divisão sexual do trabalho se multiplicaram e mostraram interessantes considerações. A desvalorização do trabalho feminino e a valorização do trabalho masculino - expressa claramente na diferença salarial e menos claramente - , mas perceptível da mesma forma - no status social atribuído à profissão — deram-se desde o momento em que as mulheres começaram a ocupar o mercado de trabalho.

Assim, ao longo do século XX e ainda no XXI a divisão sexual do trabalho persistiu. Modificaram-se suas formas, mas ela continua presente, atuante, segregadora.

Fonseca (2000, p. 93-95), ao estudar a divisão sexual do trabalho em duas fábricas no Brasil, mostra como essa questão ainda se faz presente:

Às mulheres-operárias destinam-se as operações de fiação, corte/costura e controle de qualidade, primordialmente; às demais mulheres, postos de secretárias, recepcionistas, auxiliares administrativas, responsáveis pelos serviços de refeitório, creche, assistência médica e social, cuidados de enfermagem etc. Poucas encontram-se em postos de chefia, seja no interior das unidades fabris, seja nos escritórios da administração. Quanto aos homens, é observado que os mesmos ocupam os postos de segurança e

13. Aqui utilizaremos o termo trabalho no seu sentido mais abrangente, ou seja, significando tanto a inserção no mercado formal ou informal, como o trabalho doméstico. 
vigilância, bem como postos de fabricação, como, por exemplo, os da tinturaria e da tecelagem, e outras atividades correlatas, como as de manutenção e regulagem das máquinas. São, contudo, prioritariamente encontrados em áreas de planejamento e controle da produção e da administração em geral, ocupando postos de chefia ou de assistentes das mesmas, podendo ser classificados, genericamente, como diretor, gerentes, supervisores, contramestres e assistentes. Isto é, embora nem todos os homens sejam chefes, a grande maioria das chefias é constituída por homens.

No tocante à área de assistência social, observa-se que a mesma se conserva como "gueto" ocupacional de mulheres, revelando estruturar-se de acordo com a tradição de privilegiar a mão-de-obra feminina nas atividades assistenciais, sejam elas desempenhadas por profissionais de Serviço Social, nutricionistas ou atendentes de enfermagem, de creche e de refeitório. (Grifos nossos)

O que se observa é que, na sociedade, há um comportamento que se espera das mulheres e outro que se espera dos homens. São consideradas profissões femininas as que congregam em si as características que se imaginam adequadas às mulheres, e são consideradas profissões masculinas aquelas que apresentam características que se esperam dos homens.

Há que se levar em conta que as conquistas femininas, hoje, escondem e mascaram a realidade da divisão sexual do trabalho. Apesar de as desigualdades persistirem, elas quase "sumiram" ou diminuíram significativamente das estatísticas. Contudo, mesmo hoje, com todas as conquistas sociais das mulheres e com as últimas modificações no mundo do trabalho - empobrecimento, competitividade, aumento da escolaridade, redução da taxa de fecundidade — , na divisão sexual do trabalho permanece ainda uma forte tendência à ocupação por sexos, ou seja, algumas profissões - apesar de já haver sinais de mudanças em seu interior — permanecem como "masculinas" ou "femininas" (Castro e Lavinas, 1992; Bourdieu, 1999; Hirata, 2002 e Costa, 2010).

Aqui, além da mediação de gênero, fazemos referência explícita à dimensão da raça/etnia, pois um aprendizado novo que a experiência dessa pesquisa nos proporcionou foi uma maior aproximação com a discussão étnico-racial, tema diretamente relacionado à discussão das relações sociais de gênero, mas sob o qual nunca havíamos nos debruçado mais seriamente. ${ }^{14}$

De fato, se há uma dicotomia entre profissões masculinas e femininas, e se as mulheres ocupam uma posição de subalternidade, ganhando menos que os homens,

14. Prova disso é que nos questionários construídos por nós para a pesquisa realizada durante o estágio pós-doutoral, a questão étnico-racial não se fez presente. 
há que se considerar que a pobreza no mundo, além de ter um gênero, tem uma cor: a pobreza é feminina e negra.

Os dados mostram, em relação à política de assistência social no Brasil, que 69\% dos que recebem Bolsa Família, 60\% dos que recebem o Benefício de Prestação Continuada (BPC) e $68 \%$ dos que participam de programas de erradicação infantil são negros. Quando se considera o IDH (Índice de Desenvolvimento $\mathrm{Hu}$ mano) entre os brancos no Brasil, ele é 0,838 , e o Brasil fica na $51^{\mathrm{a}}$ posição mundial. Mas ao considerarmos a população negra, o IDH é de 0,753, e o Brasil cai para 95 posição. O Brasil é hoje o país que apresenta a maior população negra depois da Nigéria, e os negros e negras representam $62 \%$ da população empobrecida no país. ${ }^{15}$ E, neste quadro, o Serviço Social é uma profissão formada prioritariamente por mulheres oriundas da classe trabalhadora e, como tal, além de mediatizada por um forte recorte de classe social, também é mediatizada por predominância de mulheres pardas ou negras. Esse também é o perfil das usuárias dos serviços sociais, a quem os(as) assistentes sociais prestam serviços.

Neste sentido, é necessário reafirmar que o feminismo e a discussão sobre divisão sexual do trabalho são atualíssimos, pois, apesar dos avanços, há muito a ser feito. As mulheres, particularmente as negras, continuam vítimas cotidianas da violência, da exclusão, da discriminação no mundo privado e público.

Deste modo, o Serviço Social - como profissão predominantemente feminina, com público usuário majoritariamente feminino e com ações voltadas para as expressões da questão social mediatizadas por questões de classe social, gênero, raça/etnia e orientação sexual - precisa, necessariamente, ter um processo de formação profissional que considere tais questões como fundamentais, e não simplesmente como discussões acessórias que não têm verdadeira centralidade no processo de formação profissional.

\section{Considerações sobre o ensino de Serviço Social no Brasil}

Como já assinalamos, os cursos de graduação presenciais de Serviço Social no Brasil seguem as diretrizes curriculares para os cursos de Serviço Social, aprovados na assembleia geral extraordinária da Abepss, em 1996.

15. Dados apresentados por Roseli Rocha, no seminário "Gênero, Raça/Etnia, Diversidade Sexual e Serviço Social” realizado na Uerj, nos dias 28, 29 e 30 de novembro de 2011. 
Tais diretrizes estabelecem três eixos básicos, sob os quais devem se estruturar os cursos de Serviço Social no país. Esses eixos, que são interdependentes e não hierárquicos, servem como elementos norteadores para organizar o processo de formação profissional e denominam-se: Núcleo de Fundamentos Teórico-Metodológicos da Vida Social, Núcleo de Fundamentos da Particularidade da Formação Sócio-Histórica da Sociedade Brasileira e Núcleo de Fundamentos do Trabalho Profissional. Os três núcleos agregam o conjunto dos componentes curriculares: disciplinas, seminários, oficinas, atividades de pesquisa e extensão e atividades complementares.

O primeiro - Núcleo de Fundamentos Teórico-Metodológicos da Vida Social - é responsável pelo estudo do ser social como totalidade histórica, analisando os componentes fundamentais da vida social. O segundo - Núcleo de Fundamentos da Particularidade da Formação Sócio-Histórica da Sociedade Brasileira - remete ao conhecimento da constituição econômica, social, política e cultural da sociedade brasileira, na sua configuração particular concreta e considerando as suas diversidades regionais e locais. O terceiro - Núcleo de Fundamentos do Trabalho Profissional - discute, analisa e estuda o Serviço Social como especialização do trabalho coletivo, que tem como objeto de atuação as múltiplas expressões da questão social. É justamente dentro desse terceiro núcleo que, a nosso ver, devem se dar as discussões mais aprofundadas sobre as relações sociais de gênero. Contudo, isso não significa que tais discussões estejam ausentes dos outros dois núcleos, pois o primeiro, ao tratar do ser social como totalidade, e o segundo, ao tratar das particularidades da realidade brasileira, devem também debater as relações de gênero que perpassam todas as dimensões da vida social.

As diretrizes curriculares foram aprovadas pelo MEC em 2001, mas passaram por forte descaracterização, uma vez que sofreram cortes que comprometeram o projeto original, especificamente no que se refere à direção social da formação profissional e aos conhecimentos e habilidades preconizados e considerados, pela categoria profissional, essenciais ao desempenho do assistente social (Iamamoto, 2007).

Deste modo, o conteúdo da formação passou a ser submetido à livre-iniciativa das unidades de ensino, desde que preservados os núcleos estruturantes assinalados anteriormente. Essa livre-iniciativa, em um contexto educacional, no qual se privilegia uma lógica mercantil e empresarial baseada na "lei" do custo-benefício, é extremamente preocupante para a formação profissional. 
Tal lógica — cujas raízes devem ser buscadas no forte processo de construção de um discurso hegemônico em torno das "virtudes" do mercado e satanização dos serviços estatais ${ }^{16}$ - enfatiza a agilidade, a eficiência, o equilíbrio financeiro e a flexibilidade das unidades privadas, apesar de o ensino das unidades públicas ser melhor. Ao enfatizar tais elementos privilegia-se uma lógica na qual o treinamento, a transmissão de conhecimentos e o adestramento tomam o lugar do conhecimento crítico e reflexivo que exige tempo para se construir e que têm na pesquisa e produção do conhecimento suas principais fontes (Iamamoto, 2007).

Nessa direção, têm proliferado no Brasil os cursos de educação à distância (EAD), os cursos sequenciais, as graduações tecnológicas, entre outras iniciativas, que têm na economia de recursos e tempo suas principais justificativas, apesar do discurso ideológico de "democratização" do acesso ao conhecimento. Tal "democratização" tem se dado, prioritariamente, por meio do aumento do número de vagas no ensino superior nas instituições privadas - financiadas com recursos públicos - e do crescimento desordenado do ensino à distância, que tem trazido forte rebatimento na qualidade do ensino ministrado aos discentes formados nessa modalidade de ensino.

$\mathrm{O}$ aligeiramento do processo formativo, sua submissão à lógica empresarial e competitiva, as "parcerias" público-privado com ênfase no mercado como fonte de recursos para financiar projetos dos docentes das universidades públicas têm sido alvo de debates acalorados entre os defensores desse projeto e os que defendem mais recursos para a universidade pública apostando no ensino público, gratuito, de qualidade e autônomo. ${ }^{17}$ Por ora, resta-nos assinalar que nos somamos aos que se preocupam com os rumos que veem sendo dados à educação em nosso país, conscientes de que conhecimento crítico e autônomo só se constrói com tempo e recursos. Neste sentido, não se concebe uma formação de ensino superior submetida à lógica do custo-benefício, da competitividade e do aligeiramento e que é obrigada a mendigar recursos para suas pesquisas no mercado. $^{18}$

16. Esse processo inicia-se no Brasil nos anos 1990, no governo do presidente Fernando Collor de Melo (1990-1992), contudo torna-se hegemônico a partir do governo de Fernando Henrique Cardoso (1995-2003).

17. Há inúmeros artigos e publicações discutindo essas questões a partir da perspectiva de defesa da universidade pública, gratuita e autônoma. Ver, entre outros, Iamamoto (2007), Abepss (2000) e PUC Viva (2009).

18. Deve-se salientar que a lógica de captação de recursos no mercado termina privilegiando setores estratégicos para o capital, uma vez que este não se interessa por algo que não vai the dar retorno financeiro 
A todas essas inquietações, de caráter mais geral, soma-se ainda a preocupação com a forma como tem se dado, nos cursos presenciais em Serviço Social no Brasil, as discussões e estudos relativos às temáticas de gênero, raça/etnia e orientação sexual. ${ }^{19}$ Temas que, a nosso ver, são considerados menos importantes no processo de formação profissional, uma vez que tem se dado nos últimos períodos dos cursos e, quase sempre de forma eletiva. Desta forma, os discentes de Serviço Social, em sua maioria e em regra geral, deixam de conhecer uma mediação importante na compreensão e explicação da questão social.

Assim, as discussões nos cursos de Serviço Social no Brasil avançaram ao se constituir em torno da "questão social" como objeto de ação profissional do Serviço Social e, neste sentido, têm priorizado as discussões em torno das classes sociais. Contudo, falta-nos ainda nos dedicarmos mais seriamente às diferentes dimensões que atravessam a questão social, ou seja, falta-nos estudar de forma mais aprofundada as demais dimensões constitutivas da questão social, a saber, gênero, raça/ etnia e sexualidade. Tais discussões não podem continuar a ser eletivas para os profissionais, como se isso não interferisse na qualidade do trabalho profissional. Deste modo, consideramos que é necessário avançarmos nessa discussão no âmbito da profissão, mas também avaliamos que a construção dos Grupos Temáticos de Pesquisa (GTPs) ${ }^{20}$ no âmbito da formação profissional em Serviço Social pode apontar caminhos de fortalecimento dessas discussões.

Os GTPs constituem-se em uma estratégia já realizada em outras áreas — a exemplo da Associação Nacional de Pós-Graduação e Pesquisa em Ciências Sociais (Anpocs) e Associação Nacional de Pós-Graduação e Pesquisa em Educação (Anped) - mas que inova ao buscar fortalecer a pesquisa no Serviço Social, articulando a dimensão do ensino-pesquisa e extensão. A perspectiva é considerar a transversalidade dos eixos teórico-históricos que orientam as diretrizes curriculares dos cursos de Serviço Social no Brasil: os fundamentos da vida social, da realidade brasileira e do trabalho profissional (Abepss, 2009).

posteriormente. Neste sentido, as ações sociais e ecológicas do empresariado são simplesmente estratégias de marketing.

19. Entendemos que a temática de gênero envolve, necessariamente, a discussão sobre classe social, raça/etnia e orientação sexual, ou seja, a temática da diversidade humana.

20. A proposta surge como estratégia gestada a partir das discussões nos eventos de Serviço Social, discutido amplamente em oficinas locais, regionais e nacional e aprovada na Reunião Ampliada da Diretoria da ABEPSS, em novembro de 2009. 
Tal processo encontra-se ainda em construção, e optou-se pela delimitação de sete áreas temáticas, ${ }^{21}$ a saber:

1. Trabalho, Questão Social e Serviço Social;

2. Política Social e Serviço Social;

3. Questões Agrária, Urbana, Ambiental e Serviço Social;

4. Serviço Social: Fundamentos, Formação e Trabalho Profissional;

5. Serviço Social, Relações de Exploração/Opressão de Gênero, Raça/Etnia, Geração, Sexualidades;

6. Serviço Social: Fundamentos, Formação e Trabalho Profissional;

7. Ética, Direitos Humanos e Serviço Social;

8. Movimentos Sociais e Serviço Social.

Deste modo, os GTPs buscam, entre outros objetivos,

romper com possíveis situações de isolamento dos pesquisadores e de suas produções, coletivizar debates de ponta, pautar temas relevantes, incidir na mudança das subáreas hoje vigentes na Capes e no CNPq [...], alimentar o debate da formação e do exercício profissionais, alimentar as publicações da área, estimular a organização de redes de pesquisa, fomentar a articulação com a pesquisa desenvolvida por UFAs e instituições de pesquisa na América Latina, África e demais continentes, constituir os eixos estruturadores do Enpess, dentre outras possibilidades. (Abepss, 2009, p. 5)

Deste modo, as discussões específicas que têm se dado sobre a construção do GTP 6 parece-nos que apontam para a superação dos desafios que indicamos.

Nos momentos de encontros nacionais do Serviço Social - como Encontro Nacional de Pesquisadores em Serviço Social e Oficina Nacional da Abepss -, a categoria aproveita para aprofundar o debate em torno dos GTPs, estratégia que, avaliamos, poderá contribuir para enfrentar os desafios postos à profissão e principalmente para conjugar esforços em torno de áreas temáticas menos "visíveis" no seio da profissão.

21. Foram criados grupos de trabalho em cada GTP para encaminhar as discussões. Vários encaminhamentos foram aprovados no XIII Enpess, realizado em Juiz de Fora de 5 a 9 de novembro de 2012. 


\section{Considerações sobre a perspectiva teórico-metodológica adotada e a análise dos dados}

Aqui, adota-se a perspectiva materialista histórica e dialética, ou seja, a realidade precede a consciência, é devir permanente, e suas transformações se dão histórica e socialmente a partir da práxis humana. Neste sentido, os homens e as mulheres são seres também históricos e sociais que transformam tal realidade, ao mesmo tempo em que são transformados durante esse processo (Marx, 1991 e 1988 e; Vásquez, 2007). Para transformar a realidade, os seres humanos precisam conhecê-la, de forma que possam, ao se defrontar com seus desafios, encontrar saídas para uma intervenção mais eficaz. Nesse processo se dá a produção de conhecimento: quando os seres humanos buscam respostas para problemáticas que os inquietam e desafiam.

No nosso caso, particularmente, nossa inquietação dizia respeito às disciplinas e grupos de pesquisa relacionados à temática de gênero no âmbito da graduação presencial em Serviço Social no Brasil. Para investigar tal objeto, como já assinalamos, analisamos um total de 54 questionários aplicados junto a docentes e discentes de universidades públicas e privadas das diversas regiões do Brasil. Desses 54, 41 foram respondidos por docentes $(75,93 \%)$ e treze por discentes $(24,07 \%)$.

Os 54 questionários apresentam a realidade das disciplinas sobre gênero nos cursos de Serviço Social presenciais no Brasil. Destes, treze questionários (onze unidades de ensino) referem-se à região Nordeste, portanto 24,07\%; dois referem-se à região Norte (duas unidades), portanto 3,70\%; 19 referem-se à região Sudeste, correspondendo a 35,19\% do total; doze referem-se à região Sul (cinco unidades), correspondendo a 22,22\%, e oito questionários referem-se à região Centro-Oeste (também cinco unidades), correspondendo a 14,81\% do total de questionários. ${ }^{22}$.

22. As unidades de ensino que participaram da pesquisa foram as seguintes: região Norte: UFAM e UFT; Nordeste: UFPE, Ufal, UFRN, UFMA, Fametro-CE, UFPB, IFCE, Uece, Uern,UEPB, UFRB; Centro-Oeste: UnB, UFMT, UFG, PUC-GO, Univag-MT; Sudeste: UFJF, Uerj, UFRJ, Ufes, UFF, PUC-Rio, Unilago São João do Rio Preto-SP, Uninove-SP, Centro Universitário Ítalo Brasileiro-SP; Sul: PUC-RS, UFSC, Unisinos-RS, Unipampa-RS, Universidade Caxias do Sul-RS. 


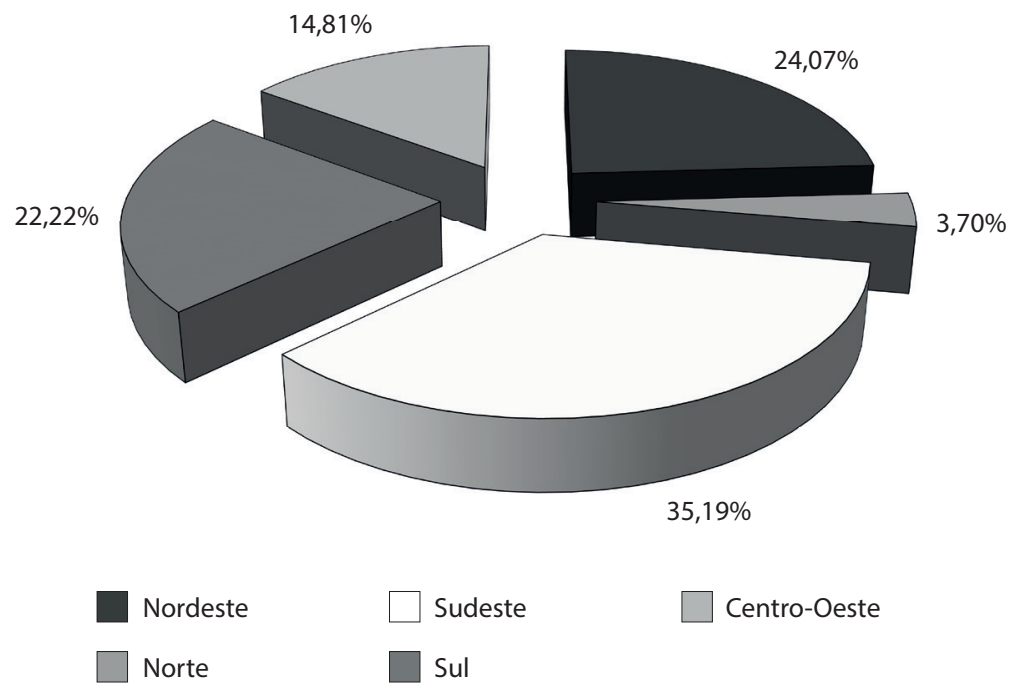

Fonte: Coleta de Dados, 2012.

Como se pode observar, a região Sudeste foi uma das que conseguimos mais dados (foram nove cursos de Serviço Social que responderam ao questionário, em um total de treze docentes e seis discentes). Isto se explica em função de a Oficina Nacional da Abepss ter sido realizada na cidade do Rio de Janeiro, o que possibilitou o deslocamento com mais facilidade de membros do corpo docente e discentes que moram ou trabalham em estados mais próximos ao Rio de Janeiro. Ao mesmo tempo, a região Norte foi a que conseguimos menos dados (dois docentes de duas universidades ao todo), o que também se explica pela dificuldade dos custos mais altos do deslocamento dos docentes e discentes da região Norte para a Sudeste, local que sediou o evento no qual coletamos os dados.

A predominância feminina entre docentes e discentes se confirma em todas as regiões. No total dos(as) entrevistados(as), 92,59\% eram mulheres e 7,41\% eram homens. Os dados separados por região somente permitem visualizar melhor que a predominância feminina é constante em todas as regiões do país, conforme a pesquisa nacional já atestava anteriormente (ver CFESS, 2005). 


\section{Gráfico 2 - Perfil dos entrevistados por sexo e região}

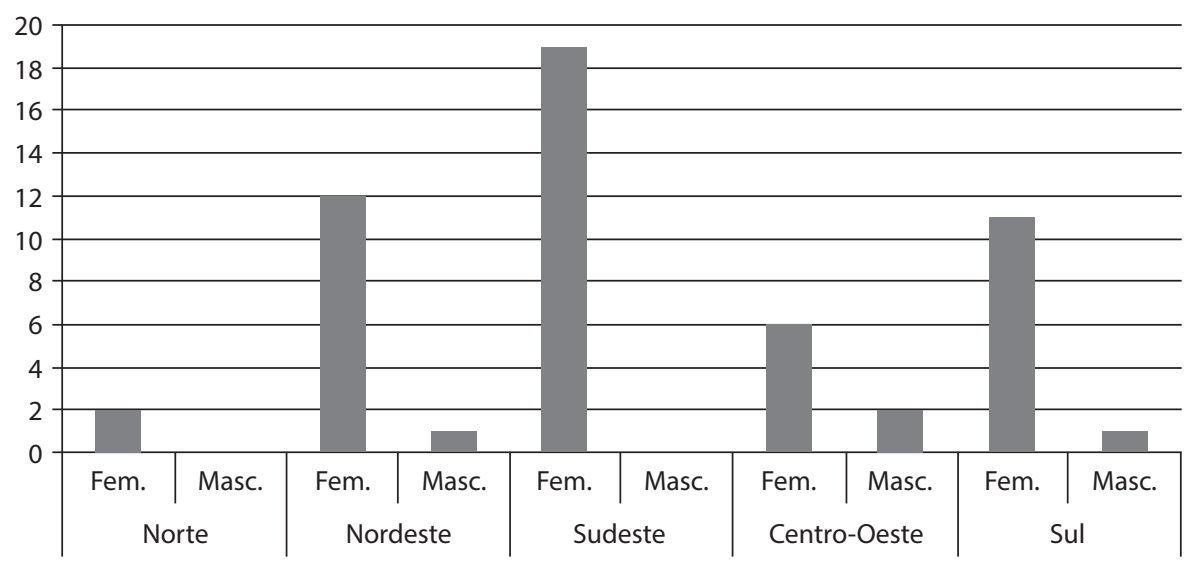

Fonte: Coleta de Dados, 2012.

É importante ainda considerar que os resultados desse estudo não têm a pretensão da representatividade e da generalização. A amostra analisada não seguiu critérios quantitativos que permitam a generalização dos resultados. Apesar disso, consideramos que os elementos detectados podem indicar algumas tendências no seio da profissão e, particularmente, no estudo das relações de gênero em seu interior.

Para efeitos de exposição, apresentaremos somente uma parte dos resultados da pesquisa que comparam os dados encontrados nas diversas regiões pesquisadas.

\subsection{Comparação entre a realidade das diversas regiões}

A fim de permitir uma comparação entre os dados das diversas regiões, optamos por destacar a moda encontrada em cada região administrativa pesquisada. A moda é o valor que detém o maior número de observações, ou seja, o valor ou valores mais frequentes encontrados nas respostas dos entrevistados (Richardson, 1999). Desta forma, a moda não é necessariamente única, pois alguns valores podem 
se repetir o mesmo número de vezes e, portanto, neste caso haverá mais de um número modal.

Quadro 1 - Moda do número de pesquisadores por região

\begin{tabular}{|c|c|c|c|c|}
\hline Norte & Nordeste & Sudeste & Centro-0este & Sul \\
\hline Pesquisadores & Pesquisadores & Pesquisadores & Pesquisadores & Pesquisadores \\
\hline 2 e 4 & 3 e 4 & 3 & 1 e 5 & 2 \\
\hline
\end{tabular}

Fonte: Coleta de Dados 2012.

Em relação ao número de pesquisadores sobre a temática de gênero, observa-se nos dados levantados que as regiões Centro-Oeste e Nordeste são as que detêm maior número de pesquisadores ligados ao tema. Já em relação aos grupos de estudo, todas as regiões do país tem um grupo de pesquisa como o número mais frequente.

Quadro 2 - Moda do número de grupos por região

\begin{tabular}{|c|c|c|c|c|}
\hline Norte & Nordeste & Sudeste & Centro-0este & Sul \\
\hline Grupos & Grupos & Grupos & Grupos & Grupos \\
\hline 1 & 1 & 1 & 1 & 1 \\
\hline
\end{tabular}

Fonte: Coleta de Dados 2012.

Em relação ao período do curso no qual a disciplina sobre gênero é ofertada, do total das cinco regiões há duas (Centro-Oeste e Sul) nas quais a disciplina é ofertada do $7^{\circ}$ período do curso, o que para nós é preocupante, pois os(as) discentes somente pagam uma disciplina sobre gênero ao estar saindo do curso e ao fim do estágio obrigatório (que em todas as regiões, via de regra, se realiza no $5^{\circ}$ período 
do curso), dificultando, portanto, a percepção, por parte deles de questões ligadas às relações sociais de gênero durante o estágio.

Quadro 3 - Moda do período da oferta das disciplinas

\begin{tabular}{|c|c|c|c|c|}
\hline Norte & Nordeste & Sudeste & Centro-0este & Sul \\
\hline $\begin{array}{c}\text { Período } \\
\text { disciplina }\end{array}$ & Período disciplina & $\begin{array}{c}\text { Período } \\
\text { disciplina }\end{array}$ & $\begin{array}{c}\text { Período } \\
\text { disciplina }\end{array}$ & $\begin{array}{c}\text { Período } \\
\text { disciplina }\end{array}$ \\
\hline 5 & 5 & 3 & 7 & 7 \\
\hline
\end{tabular}

Fonte: Coleta de Dados 2012.

Quadro 4 - Moda do período do curso da oferta de estágios por região

\begin{tabular}{|c|c|c|c|c|}
\hline Norte & Nordeste & Sudeste & Centro-0este & Sul \\
\hline Período estágio & Período estágio & Período estágio & Período estágio & Período estágio \\
\hline 5 & 5 & 5 & 5 & 5 \\
\hline
\end{tabular}

Fonte: Coleta de Dados 2012.

Por fim, os dados também mostram que na maioria das regiões pesquisadas as disciplinas que se dedicam a estudar relações sociais de gênero são eletivas (com exceção da região Sudeste, cuja moda foi disciplina obrigatória).

Quadro 5 - Moda do número de disciplinas e caráter por região

\begin{tabular}{|c|c|c|c|c|}
\hline Norte & Nordeste & Sudeste & Centro-0este & Sul \\
\hline $\begin{array}{c}\text { N. e caráter das } \\
\text { disciplinas }\end{array}$ & $\begin{array}{c}\text { N. e caráter das } \\
\text { disciplinas }\end{array}$ & $\begin{array}{c}\text { N. e caráter das } \\
\text { disciplinas }\end{array}$ & $\begin{array}{c}\text { N. e caráter das } \\
\text { disciplinas }\end{array}$ & $\begin{array}{c}\text { N. e caráter das } \\
\text { disciplinas }\end{array}$ \\
\hline 2 eletivas & 1 eletiva & 1 obrigatória & 1 eletiva & 1 eletiva \\
\hline
\end{tabular}

Fonte: Coleta de Dados 2012. 


\section{Considerações finais a partir dos dados levantados}

Do ponto de vista da pesquisa sobre a realidade dos grupos de pesquisa, pesquisadores e, principalmente, como se configuram as disciplinas que discutem a temática de gênero nos cursos de Serviço Social presenciais no Brasil, a oficina nacional da Abepss, realizada na UFRJ em novembro de 2011, permitiu-nos o contato com 32 universidades (entre públicas e privadas), de todas as regiões do país, dando-nos um retrato, que consideramos aproximado, das questões que nos interessavam.

Neste sentido, avaliamos que a temática tem conquistado espaço e crescido na profissão, principalmente a partir da constituição dos GTPs, que, como assinalamos, consideramos uma importante iniciativa que possibilita aprofundar as discussões em torno de temáticas. Contudo, ainda se faz necessário avançar mais no processo de formação dos discentes, uma vez que as discussões têm se dado em disciplinas eletivas e, por vezes, somente ao final do curso.

Outro elemento que consideramos importante é incorporar de forma mais efetiva nos grupos que estudam gênero as discussões sobre etnia/raça, diversidade sexual e questões éticas. Essas mediações se fazem presentes no cotidiano das mulheres e dos homens e, portanto, precisam ser mais bem aprofundadas no processo de formação nos cursos de graduação de Serviço Social.

Deste modo, a título de sugestão, apresentamos as seguintes propostas para os cursos de graduação em Serviço Social no Brasil:

- A temática de gênero deve se dar em forma de disciplina obrigatória e no momento de ingresso dos discentes no estágio obrigatório.

- A temática de gênero deve incorporar mais efetivamente discussões relacionadas à etnia/raça, diversidade sexual e questões éticas.

- A temática de gênero deve se dar também transversalmente, nas diversas disciplinas do curso, relacionando tal temática com as demais.

Recebido em 20/3/2013 - Aprovado em 2/12/2013 


\section{Referências bibliográficas}

ABEPSS. Temporalis, revista da Associação Brasileira de Ensino e Pesquisa em Serviço Social. Brasília, ano I, n. 1, jan./jun. 2000.

. A Abepss e o Fortalecimento da Pesquisa na Área de Serviço Social: a estratégia dos Grupos Temáticos de Pesquisa (GTPs). Documento final referendado no Seminário Nacional de Pesquisa e Pós-Graduação e aprovado na Reunião Ampliada da Diretoria da Abepss em 28 de novembro de 2009. Disponível em: <http://www.abepss.org.br/briefing/ documentos/GTPs_Novembro_de_2009_Final.pdf>. Acesso em: 6 dez. 2012.

ARAÚJO, Clara. Marxismo, feminismo e o enfoque de gênero. Crítica Marxista, São Paulo, n. 11, out. 2000 .

BARBIERI, Terezita. Sobre a categoria gênero: uma introdução teórico-metodológica. Tradução de Antonia Lewinsky. Recife: SOS Corpo, 1993.

BOURDIEU, Pierre. A dominação masculina. Tradução de Maria Helena Kühner. Rio de Janeiro: Bertrand Brasil, 1999.

CASTRO, Mary G.; LAVINAS, Lena. Do feminino ao gênero: a construção de um objeto. In: BRUSCHINI, Cristina; COSTA, Albertina de Oliveira (Orgs.). Uma questão de gênero. Rio de Janeiro/São Paulo: Rosa dos Tempos/Fundação Carlos Chagas, 1992.

CFESS (Org.). Assistentes sociais no Brasil: elementos para o estudo do perfil profissional. Brasília: CFESS, 2005. Disponível em: $<$ http://www.cfess.org.br/pdf/perfilas_edicaovirtual2006.pdf>. Acesso em: 15 jan. 2011.

COSTA, Albertina et al. (Orgs.). Divisão sexual do trabalho, Estado e crise do capitalismo. Recife: SOS Corpo, 2010.

ERGAS, Yasmine. O feminismo dos anos 1960-1980. In: THÉBAUD, F.; DUBY, G.; PERROT, M. História das mulheres no Ocidente: o século XX. Tradução de Maria Helena da Cruz, Irene Maria Vaquinhas, Leontina Ventura e Guilhermina Mota. Porto: Edições Afrontamento, 1991.

FONSECA, Claúdia. Uma genealogia do "gênero". Revista de Antropologia, Recife, v. 1, n. 2, [1995]. (Série Família e Gênero.)

FONSECA, Tânia Mara Galii. Gênero, subjetividade e trabalho. Petrópolis: Vozes, 2000.

GOMÀRIZ, Enrique. Los estúdios de género y sus fuentes epistemológicas: periodización y perspectivas. In: RODRÍGUEZ, Regina. Fin de siglo: género y cambio civilizatorio. Santiago: Isis Internacional, 1992. 
HECKERT, Sonia Maria Rocha. Identidade e mulher no Serviço Social. Serviço Social \& Sociedade, São Paulo, ano XII, n. 36, ago. 1991.

HIRATA, Helena. Nova divisão sexual do trabalho? Um olhar voltado para a empresa e a sociedade. São Paulo: Boitempo, 2002.

IAMAMOTO, Marilda V. Relações sociais e Serviço Social no Brasil: esboço de uma interpretação histórico-metodológica. 2. ed. São Paulo/Lima: Cortez/Celats, 1983.

. O Serviço Social na contemporaneidade: trabalho e formação profissional. São Paulo: Cortez, 1998.

. Projeto profissional: espaços ocupacionais e trabalho do(a) assistente social na atualidade. In: . Atribuições privativas do(a) assistente social em questão. Brasília: CFESS, 2002.

. Serviço Social em tempo de capital fetiche: capital financeiro, trabalho e questão social. São Paulo: Cortez, 2007.

KERGOAT, Daniele. De la condition feminine aux raports sociaux de sexes: Repères pourune évolution de la définition sociologique des catégories de sexe. (Exposé fait dans le séminaire dans le Université de Provence, sur le thèrne: "La división sociale du travail"). Aix-en-Provence, jun. 1984.

LIMA, Rita de Lourdes de. Os assistentes sociais e a questão da subalternidade profissional: reflexões acerca das representações sociais do ser mulher e do Serviço Social. Tese (Doutorado) - Universidade Federal de Pernambuco, Recife, 2005.

MARX, Karl. O capital: crítica da economia política. São Paulo: Bertrand Brasil, 1987. Livro I, v. I.

v. V.

. O capital: crítica da economia política. São Paulo: Nova Cultural, 1988. Livro III,

; ENGELS, F. A ideologia alemã (Feuerbach). 8. ed. Tradução de José Carlos Bruni e Marco Aurélio Nogueira. São Paulo: Hucitec, 1991.

OSTERNE, Maria do Socorro F. Familia, pobreza e gênero: o lugar da dominação masculina. Fortaleza: EDUECE, 2001.

PUC VIVA. Revista da Associação de Professores da PUC-São Paulo, São Paulo, ano 10, n. $35,2009$.

RICHARDSON, R. J. et al. Pesquisa social: métodos e técnicas. 3. ed. São Paulo: Atlas, 1999.

ROCHA-COUTINHO, Maria Lúcia. Tecendo por trás dos panos: a mulher brasileira nas relações familiares. Rio de Janeiro: Rocco, 1994. 
SAFFIOTI, Heleieth. Quem tem medo dos esquemas patriarcais de pensamento? Critica Marxista, São Paulo, n. 11, out. 2000.

SCOTT, Joan. Gênero: uma categoria útil de análise histórica. Educação e Realidade, Porto Alegre, v. 16, n. 2, jul./dez. 1990.

TARNAS, Richard. A epopeia do pensamento ocidental: para compreender as ideias que moldaram nossa visão de mundo. Rio de Janeiro: Bertrand Brasil, 2000.

TOSCANO, Moema; GOLDENBERG, Mirian. A revolução das mulheres: um balanço do feminismo no Brasil. Rio de Janeiro: Revan, 1992.

VÁSQUEZ, Adolfo S. Filosofia da práxis. São Paulo: Expressão Popular, 2007.

VELOSO, Renato. No caminho de uma reflexão sobre Serviço Social e gênero. Praia Vermelha, Rio de Janeiro, v. 2, n. 4. UFRJ, Programa de Pós-Graduação da Escola de Serviço Social, $2^{\circ}$ sem. 2001. (Estudos de Política e Teoria Social.)

VERDÈS-LEROUX, Jeannine. Trabalhador social: prática, hábitos, ethos e formas de intervenção. Tradução de René de Carvalho. São Paulo: Cortez, 1986. 